\title{
Routines: towards the Complexity of Organizational Intentionality
}

\author{
Piotr Tomasz Makowski ${ }^{1}$
}

Accepted: 7 June 2021/Published online: 23 June 2021

(C) The Author(s) 2021

\begin{abstract}
The paper explores the topic of organizational routines from a philosophical vantage point to see how the philosophy of action may help improve its understanding in organizational research. The main goal is to show the distinctive complexity of the intentional picture of routines. In this respect, the paper clarifies the interrelations between psychological habits and routines and describes similarities and differences between them. It also highlights the special place of mindfulness as a psycho-cognitive mechanism of action meta-control in intentional explanations of routine complexity.
\end{abstract}

Keywords Organizational routines $\cdot$ Habits $\cdot$ Mindfulness · Intentionality · Complexity · Action theory

\section{Introduction}

Organizational routines hold an important place in theories of organizational behavior and strategy. They have been conceptualized in various ways, but two approaches prevail: routines as organizational capabilities or dispositions for repeated performance and routines as repetitive patterns of collective organizational actions. The former approach highlights abilities and resources, the latter-practice and performance (see, e.g.: Parmigiani and Howard-Grenville 2011). The category of routines is thus quite broad. Regardless the conceptualization, the category embraces a whole variety of actions: standard operating procedures (such as safety) which-when followed regularly_bring standardization and stability, organizational meetings (faculty, board of directors, etc.) having a certain formal or informal structure and predictable pattern, recruitment practices which require sequences of activities that may be dynamically adjusted to organizational needs, and so forth. There is a decades old tradition of

Piotr Tomasz Makowski pmakowski@wz.uw.edu.pl

1 Faculty of Management, University of Warsaw, U1. Szturmowa 1/3, 02678 Warsaw, Poland 
studying routines - their organizational and strategic dimensions and roles, social and practical dynamics, along with their cognitive and psychological underpinnings.

Although routines may be conceived as collective actions of a special kind, philosophy of action has only minimally and one-sidedly been engaged to investigate their nature. Occasionally, philosophical accounts (like the Deweyan pragmatism) are used in routines research to develop the theory (Dittrich and Seidl 2018; Cohen 2007), but not the other way around: so far, philosophers of action themselves have not paid attention to organizational routines. There is no philosophical take on routines qua intentional actions. This text is intended to change this somewhat peculiar situation.

In routines research - embracing highly diversified views, additionally divided by cognitive and sociological perspectives that do not often communicate with one another (Parmigiani and Howard-Grenville 2011) - it has been well recognized that routines are practically complex and dynamic (Hærem et al. 2021). Routines may be more or less automatic or flexible as actions, depending on various practical and organizational factors. This is especially clear for sociological, practice-oriented scholarship (Feldman et al. 2021; Feldman et al. 2019). Still, this understanding has not, so far, been paired by equal attention to the complexity of psycho-cognitive or intentional underpinnings of routines understood as actions, which makes that understanding incomplete.

The approach I would like to propose aims to fill this gap. It ties together the question of the nature of organizational routines with philosophical investigations of their intentional underpinnings. From the perspective of the analytic philosophy of action (or action theory), these investigations may be marked either by the Anscombean or Davidsonian tradition which focuses on such standard cases of propositional attitudes as individual and shared intentions or by the psychology-inspired tradition which focuses on lower cognitive processes and dispositions frequently conceived as nonpropositional and implying automaticity and habitual actions. The nature of routines initially suggests rather the second type of investigation, but - as we shall see-a comprehensive picture of their intentional complexity must go beyond it.

Although the ideas of automaticity and habitual behavior have been present in routines research since its beginnings, they did not adequately capture the complexity of routines on the level of practice which has been recognized in the sociological lens. This issue especially concerns the flexibility and mindfulness of routines. A better understanding of intentional underpinnings that integrate together the psychological micro-level conditions of automaticity and flexibility may advance not only knowledge of routines and their practical implications for organizational psychology (e.g. regarding suboptimal performance), but also contribute to the research on integrative mechanisms for cognitive-automatic control of actions in psychology and empirically informed action theory.

The specific task of this paper is therefore twofold. First, I am going to elucidate one of the most important conceptual relations for routines research, namely the relationship between organizational routines and psychological habits. Second, I highlight the role of mindfulness (or psychological flexibility) that on the macro-level appears to be one of the distinctive properties of many routines that significantly contribute to their complexity. Since mindfulness and flexibility are themes that hitherto have not received much attention in philosophy of action, one has additional reason to explore the theme of routines from a philosophical perspective. 
The structure of the essay is as follows. Firstly, I give an overview of the characteristics of routines and tie them to the most popular themes in the literature of the subject. Then I move the discussion to the area of action theory, where, after introducing the context of automatic and habitual actions, I explain the similarities and differences between psychological habits and organizational routines in more detail. In the third step, I turn back to the routines literature and explore how the relation between habits and routines is basically understood in organizational research. As the discussion of habits and routines unveils the complexity of the latter category, in the last section, I offer a brief account of the idea of the mindfulness of routines, which is one of the key factors of that complexity on the psycho-cognitive level. I wrap up with remarks showing how the the intentional complexity perspective broadens and supplements current approaches to complexity available in routines research.

\section{Preliminary Characteristics and the State-of-the Art}

The greatest theoretical worry concerning the idea of routine action seems to be related to the fact that it is an umbrella concept embracing a whole variety of actions. Routines can be very simple, automatic and mindless, such as when surgeons wash their hands before they enter an operating room or when engineers put on hardhats in hazardous construction zones. They can also be quite complex, ordered and require much deliberation and attention: like safety operations in nuclear power plants or aircraft maneuvers in the extraordinary circumstances such as emergency landings. These examples imply that behind a routine there is a clearly defined procedure that gives them a formal-organizational dimension. Even if an action is performed mindlessly (e.g. a worker putting on a hardhat), it makes sense in the light of a procedure (e.g. safety regulations) which must be appropriated and familiarized (via instructions and trainings) before the action takes place.

Routines may also exist and be performed even if there is no formal procedure, codification or anything written down or communicated explicitly. For example, certain ways of reporting to a supervisor by an employee or recruitment practices. In those instances, the organizational and cooperative dimension and pattern of a routine comes directly from practice, repetition and learning through exercise. Routines as behavioral patterns may exist implicitly without needing to be named or described as a certain standard or rule. Routines backed by preexisting procedures or explicit rules appear more or less stable and invariant, while routines constituted by repetitive practices seem to be rather mutable and fluctuating.

Furthermore, although from the organizational perspective routines are typically perceived as collective phenomena, they may be performed both individually and collectively. An engineer wearing a hardhat is a solo agent performing his or her routinized activity individually, but the very wearing of it gains an organizational and collective meaning because it contributes to the repetitive pattern, stability and safety on the macro-scale of actions performed in the construction zone by all those who work there (and follow the routine). On the other hand, the routine serving of refreshments in an aircraft by flight attendants is a cooperative activity that requires an interdependence of activities and a high dose of collective intentionality from the whole team, so it cannot be an individual activity in typical circumstances. 
The initial characteristics and labeling provided above suggest not only high conceptual heterogeneity, but also the salience of certain themes in routines literature. Historically, the procedural, automatic or 'scripted' dimension of routines has been related to such themes as organizational programs (March and Simon 1958) which bring stability and save resources (no need for explicit decision-making); genes (Nelson and Winter 1982) which are organizational analogues of biological genes-predictive patterns that program organizational behavior and provide the mechanism of its evolution; or so-called scripts (Ashforth and Fried 1988), cognitive structures which mindlessly bring routinization and ordering of organizational behavior.

The mutability, flexibility and mindfulness of routines is highlighted in practice theory- and sociology-driven accounts which reject the idea of simple automaticity of routines and prefer to see them as 'effortful accomplishments' (Feldman and Pentland 2003; Feldman 2000; Pentland and Rueter 1994). According to this perspective (called 'routine dynamics' (Feldman et al. 2019; Feldman et al. 2021)), routines are basically dynamic, so they should be perceived rather as a source of organizational transformations and change than something rigid or inert due to being repetitive, programmed or automatic. The latter characteristics - if they appear-belong to their more fundamental performative dynamics. For example, the enactment of a given hiring procedure may be relatively stable or rigid over a certain period of time, but it may change due to typically practical demands (a video interview may replace an in-person interview because of certain environmental hazards or because it is better suited to the psychological profiles of the candidates). This is why the same camp prefers to consider routines as rather enacted or performed by the 'logic of practice' (inspirations from Bourdieusian sociology) than simply defined, codified or scripted (although they recognize the need for considering routines in both these dimensions). In the context of automaticity-related views, this take brought substantial disagreement concerning the nature of routines. ${ }^{1}$

Another noticeable theme is the problem of how routines emerge from other organizational phenomena or from various micro-level factors which frequently require special approaches to organizational intentionality and cognition-action links (Dittrich and Seidl 2018; Gao et al. 2014; Bapuji et al. 2012; Witt 2011).

Current debates concerning the intentional picture of routines are also significantly shaped by two other related perspectives rooted in organizational economics. One of them is related to the aforementioned idea that routines are operational and administrative capabilities (human and physical abilities and resources) that can be actualized via repetitive performance and which reinforce organizational stability (Dosi et al. 2000; Zollo and Winter 2002). The second one focuses on the cognitive underpinnings of routines, which highlights such themes as procedural memory, psychological automaticity and psychological habits (Cohen 2012, 2007; Cohen and Bacdayan 1994; Winter 2013). ${ }^{2}$ A somewhat broader approach is represented by the so-called microfoundations movement which also investigates other non-intentional micro-level factors, e.g. organizational structure and processes, to trace the micro-causes of routines (Foss and Linder 2019; Felin et al. 2012).

\footnotetext{
${ }^{1}$ Attempts to bridge the gap between the two main approaches exist (Parmigiani and Howard-Grenville 2011; Pentland and Rueter 1994; Levinthal and Rerup 2006), but they did not generate sufficient consensus to solve this important conceptual worry.

${ }^{2}$ Cognitive underpinnings of routines can be understood as a special form of capabilities since the latter category embraces also cognitive abilities of organizations (such as human skills) (Eggers and Kaplan 2013).
} 


\section{Routines from the Perspective of the Philosophy of Action}

The conceptual challenges that arise from the organizational literature on routines reveal that the concept of routine is entangled in questions typical for the philosophy of action. Indeed, it has already been recognized that the idea of action is central for routines (Feldman et al. 2016; Feldman 2016), but relatively little has been precisely said about it, especially when it comes to the question of intentionality. Philosphy of actions appears to be especially well suited to respond to this concern. Here I would like to raise two basic issues which potentially situate routines at the heart of actiontheoretical questions. One is related to the very possibility of conceiving routines qua actions, the other-to their intentional profile.

Firstly, the competitive conceptualizations of routines, e.g. as capabilities for performance and patterns of collective practice, appear to be two ways of looking at the same phenomenon: the first one points to their cognitive-intentional conditions and the second one highlights their performative dimension. Still, some authors produced arguments that contributed to unnecessary conceptual polarizations. Consider the following:

...routines are not behaviour; they are stored behavioural capacities or capabilities. These capacities involve knowledge and memory. They involve organisational structures and individual habits which, when triggered, lead to sequential behaviours (Hodgson 2003: 376).

By the same token, one could say that habits are not actions, because they are behavioral dispositions. In action theory, such reactions may be misleading, because they build unnecessary gap between the agentive, intentional conditions of actions and their performance. It is true that the standard stance in the analytic philosophy of action approaches human agency through the prism of intentionality understood as standard propositional attitudes: desires, beliefs and intending. But in this perspective, the performative or enactive dimension of action appears as rather the other, implicit side of the coin of intentionality. This approach is typical, for example, for the Davidsonian model of action (Davidson 1963) in which the practical, performative dimension of actions gives way to the analysis of their intentionality.

But if we refer the above issue to the conceptualizations of routines as collective behavior or behavioral capabilities, the difference should be interpreted rather as a change in perspective than a reason for serious disagreement between those who prefer to understand them through one of those research lenses. The philosophical distinction between the mental or linguistic representation of action (the cognitive or intentional basis of which can be analyzed further) and the action (performance or enactment) itself would help avoid several conceptual deficiencies in routines research. For instance, a routine understood as a formal procedure may refer only to certain linguistic representations of a certain symbolic shape (e.g. a list of rules or tasks) without including their performative enactment (e.g. practical implementation of those rules or tasks). On the other hand, routines in highly informal, self-managed organizations may be based on practice, with their representational dimension not going beyond the intentional conditions of performing actions (which may be - due to their informational encapsulation and intransparency - unavailable to those who perform them). Furthermore, every 
routine must have a representational dimension if it is identified (e.g. by managers) as something that builds organizational practice and strategy. These distinctions are not always fully recognized or expressed in clear terminology. ${ }^{3}$ In this light, action theory has the chance to ameliorate conceptual standards in the understanding of routines. Routines are intentional and enacted by organizational agents, so they are actions (and this should reconcile the proponents of the capabilities and practice perspectives).

Secondly, the nature of the intentionality of routines is directly related to conceiving them as either automatic or mindful. The picture of routine intentionality certainly changes when one moves from the example of surgeons automatically washing their hands to the example of engineers mindfully checking radiation levels in nuclear power plants. Although there are attempts in the literature to explicitly explore the picture of routine intentionality, these attempts do so without using the themes and conceptual tools of philosophy of action and do not explicitly discuss the tension that is inherent to the automaticity/mindfulness divide. For example, the only comprehensive analysis of intentionality by Dittrich and Seidl (2018) accepts the classic (Deweyan) pragmatism as a conceptual framework, which provides good intuitions about how intentionality is constituted through actions, but it does not provide sufficiently fine-grained micro-level psycho-cognitive analysis of that constitution. In this perspective, what counts for the intentional picture of routines is the dynamics of new action goals as emerging from the means embedded in certain situations - not the psycho-cognitive basis of this dynamics. It is rather plain that this perspective has its limitations in the light of the most recent developments in the philosophy of individual and collective agency, in which a certain level of detail is important to grasp the psychological complexity of actions, especially where issues related to intentional control are concerned. ${ }^{4}$

Other works refer to such standard issues as intentions (Bapuji et al. 2012) or even highlight the problem of "the full spectrum of intentionality" (Feldman 2016; Feldman et al. 2016), but without noticing the context of standard philosophy of action. On the other hand, those works which are devoted to bridging the automaticity/mindfulness divide do not usually explore the question of practical intentionality explicitly (Levinthal and Rerup 2006). In fact, the idea of action in routines research is standardly associated with the viewpoints of sociology and practice theory (Danner-Schröder 2020; Feldman Martha and Orlikowski 2011), which by definition cannot provide fine-grained accounts of agency. ${ }^{5}$

The above challenges related to the idea that routines are actions pave the way to accept the action-theoretical approach. The picture of routines it provides may be not only interesting for philosophical accounts of agency focused on automaticity and habitual actions, but also explanatorily useful for routines research.

\footnotetext{
${ }^{3}$ Note that Becker's work (Becker 2005), which approaches routines from the perspective of economics, recognizes their importance. Still, despite the visibility of his paper in the mainstream routines research, the distinction between action and representation has not been fruitfully exploited in other conceptual works. See also (Makowski 2020a).

${ }^{4}$ This is not the only challenge Deweyan pragmatism faces (e.g. his idea of habit implies that it does not have to be repetitive, which is at odds with contemporary psychology of habit, see 3.2.). A comprehensive assessment of the usefulness of Dewey's ideas in contemporary philosophy of action has yet to be produced. 5 There are strong trends against nuance in sociology (Healy 2017), while practice theory itself is known for its typically skeptical attitude towards analytic distinctions, usually interpreted as "dualisms" (Fox 2006).
} 


\subsection{Automatic Actions}

In action theory automatic actions are not easily definable because of significant divergence concerning the extent to which they require propositional attitudes (mainly intentions), higher cognitive processes responsible for decision-making and agentive control (cf. Brownstein 2014; Railton 2009; Douskos 2017a). For the present purposes it will be sufficient to roughly say that the category of automatic actions embraces those actions which are fluent and performed without thinking or deliberation. Whether they must be explained by means of the standard framework of the intentional accounts of Davidsonian provenience (cf. Schlosser 2020) which imply causal roles for propositional attitudes or by other means (Makowski 2017, chap. 6; Di Nucci 2013, chap. 6) is a matter of dispute. Still, the fact that they count as actions also implies that they are no less intentional than those which necessarily require full-blooded intentions, desires and beliefs to perform them.

Philosophical work on automatic actions encompasses various topics, among which two themes are the most frequent: motor skills (as in the case of sports, e.g. playing football or hockey) and habits (as in the case of social or psychological habits, e.g. taking off a hat when entering a church or brushing one's teeth in the morning). These themes are so common not only because they intuitively capture the idea of automatic, fluent performance, but also because an action-theoretical understanding of automaticity is to a significant extent based on classic accounts of automaticity in social and cognitive psychology (Moors and De Houwer 2006; Bargh 1994, 1996; Fiedler and Hütter 2014) where skills and habits constitute a very broad spectrum of examples (Orbell and Verplanken 2010; Verplanken 2006; Logan 1985; Wood 2017; Wood and Rünger 2016; Neal and Wood 2009; Stanley and Krakauer 2013).

As noted, the theme of the automaticity of organizational routines has been present both in classic works and in newer cognitive-psychological approaches. In this respect, Herbert Simon's and Jim March's idea of performance programs and Blake Ashford's and Yitzhak Fried's idea of mindless organized behavior resulting from following so-called scripts share similar assumptions when it comes to the role of lower cognitive processes as in the case of John Bargh's classic work in psychology: humans have strong tendencies to automatize their behavior and perform without using complex deliberation due to their bounded mental resources. It is, therefore, of no surprise that some of the later cognitive approaches to routines refer to Bargh's work explicitly (Winter 2013), giving more and more arguments to tie routines to habits. However, explicit references to the psychology of automaticity are rather scarce, although the very topic of habit has been present in the routines research for a long time (see: Louis and Sutton 1991). In this respect, there is a whole variety of inspirations spanning from the pragmatistic accounts (Cohen 2007), through the sociological idea of habitus (Bourdieu) to modern psychology (Turner and Cacciatori 2016).

If this is so, if routines have been tied to such salient topics in psychology as automaticity and habitual action, the relation between organizational routines and psychological habits cannot be easily ignored (cf. Dittrich and Seidl 2018) and requires more detailed investigation. Two questions arise: (1) what makes them similar to one another, or what are the shared features of their intentional pictures? 
(2) How is it that some accounts explicitly reject the idea that routines may be automatic in the similar sense that habits are according to psychology? These questions stem directly from the idea that routines are actions which are in some aspects and contexts automatic. So far, this idea has not been plainly discussed in the literature on routines, but it is certainly needed to better understand their intentionality. Before I try to answer the above questions, a few remarks about the psychological concept of habit are in order. ${ }^{6}$

\subsection{Habits in Psychology}

In social and cognitive psychology, habits are commonly defined as individual dispositions which are acquired through reiterative responses to context-dependent cues (Wood and Rünger 2016; Verplanken 2006; Orbell and Verplanken 2010; Neal et al. 2012; Labrecque et al. 2017; Orbell and Verplanken 2015). They form context-response associations of limited cognitive penetrability. These associations are then transformed into automatic, inertial or inflexible responses, which are difficult to break and can be integrated into sequences (Smith and Graybiel 2013). They feature automaticity both in the way they are triggered and in the way they are performed (Gardner et al. 2016). This means that habitual responses may be activated without awareness (as when entering a church activates taking off a hat) or with full awareness (as in the case of purposively going to the library to get into the mood for studying). But in both cases, it seems that overt decisions and intentions need not be formed (Wood and Rünger 2016; Bargh 1994; Douskos 2017a). Habits may be actuated by various cues-by the physical and social environment, and by prior performances.

In a few respects, habits appear to be similar to motor skills: they are smooth and fluent (Verplanken 2006) and may be performed without deliberation, freeing up mental resources (allowing for dual task performances). There are also differences between them: habits are reiterative in an inertial way, while the repetitiveness of skills implies progress and development; habits are impulsive and triggered by memory, while skills are rather spontaneous and triggered by attentional sensitivity to certain goals (Douskos 2017b).

An important problem related to habits is the question of how they fit into the picture of deliberate goal striving and mechanisms of behavioral control and change. In the classic work of John Dewey (1922), this problem was solved by a significant broadening of the concept of habit so that it also embraced the forms of habit "infused with thought and feeling" (Dewey 1922: 71) and with control from the conscious will. In modern psychological works, these issues are now usually addressed by the research on the interdependence between habits and conscious goal pursuit. This research can be summed up in the so-called 'three-pronged model' (Wood and Rünger 2016; Wood 2017). According to the model, habits and goals are interrelated through: (1) formation: habits initially stimulate agents to replicate behavior and to activate it in specific practical contexts; (2) performance: habits are frequently consciously available as goals (deliberate habit activation as in the already mentioned case of going to the library to

\footnotetext{
${ }^{6}$ In the following section I give my own synthetic presentation of the concept of habit that is based mainly on the newest psychological accounts and on selected insights from the philosophy of action.
} 
work) providing default patterns of behavior which change when actors are motivated and able to adjust their behavior to current circumstances, and finally-(3) inferences about further goals: habits are prompters for practical reasoning and decision-making. ${ }^{7}$

Thus, habits and deliberation about goals are interconnected to a great extent, and this makes that the automaticity of habitual actions cannot be simply mechanical as it is potentially within the control of deliberation and conscious willing. ${ }^{8}$ This is, partially, the reason why tagging habitual automaticity as mindless is sometimes avoided in psychology (Saling and Phillips 2007). Still, picturing habits as automatic seems to a large extent justified: if one does not place them in a fuller agentive context (as described in the three-pronged model), they appear to be (almost by definition) insensitive to changes in outcome value as they operate in 'open loops': “once an action sequence is launched, the actions in the sequence will be executed automatically up to the end of the sequence" (Dezfouli et al. 2014: 2).

\subsection{Habits and Routines: Main Similarities and Differences}

Now, although in psychology the concepts of habit and routine are sometimes used interchangeably, in organizational research they are now usually distinguished. ${ }^{9}$ The distinction, however, has not been so far made clear or explicit. The difference is usually taken for granted and it becomes visible especially in the widely accepted view that habits are building blocks of routines (Winter 2013; Cohen 2012; Cohen et al. 2014; Knudsen 2008; Parmigiani and Howard-Grenville 2011; Turner and Cacciatori 2016). This view implies difference between the two concepts, but there must also be some similarities between them. Tacit assumption concerning these two issues deserves a little more philosophical attention. Thus, some clarifications of the relation between habits and routines will not only be helpful for theory building, but they may contribute to better circulation of meanings of basic concepts which structure research in the social sciences.

Although organizational routines are considered to be different from psychological habits in newer routines research, it turns out they share several features. Let us begin with a list of basic similarities.

\footnotetext{
${ }^{7}$ However important this model is for the proper understanding of interrelations between habits and deliberation, it rarely affects the scientific image of habits in philosophy and cognitive sciences. This is so probably because psychological research on habits has been related to the dual-process model of social information processing (Chaiken and Trope 1999; Wood et al. 2014). A perfunctory reading of this model may suggest dualism between higher and lower cognitive processes.

${ }^{8}$ Naturally, this does not mean that habits are always successful. Unintended errors, so called slips (Wood and Rünger 2016; Dezfouli et al. 2014; Norman 1981), may always appear. In this light, the three-pronged model emphasizes the need for monitoring and controlling one's habits to maintain their fluency. This theme was studied empirically in many contexts: time pressure (Wood et al. 2014; Labrecque 2015), absentmindedness (Wood et al. 2014; Labrecque et al. 2017), limited task ability (Hay and Jacoby 1996, 1999), lowered motivation (Neal et al. 2013) and other willpower restrictions such as addictions (Muraven et al. 2005), temptations (Quinn et al. 2010), or stress (Schwabe and Wolf 2010, 2013).

9 This interchangeability may be a source of confusion. My initial academic contact with some of the leading psychologists of habit resulted in misunderstanding of the main idea of the research project to which this paper belongs.
} 
(1) Automaticity. Both habits and routines may be understood in many cases to be flat-out automatic. If a routine is relatively simple and does not require a high dose of cooperation from other agents, its micro-level performance (enactment by an individual agent) may simply be habitual. In fact, certain organizational routines may seem indistinguishable from habits if one considers them from an agent's point of view - in abstraction from their typical organizational contexts: procedures, formal rules (if they exist) or from their roles in broader organizational practices. Consider, again, such examples of routines as: surgeons washing their hands before entering an operating room or engineers putting on hardhats in construction zones. Full-blooded decisions or intentions are not necessary to enact such routines, so their performative dynamics is minimal. Very basic routines may seem even mindless in the same way as psychological habits: they are performed without thinking, almost blindly. And as it has been recognized both in routines research and in the psychology of habit, this may result in inertia and errors.

(2) Stability. Habits provide behavioral stability due to reiterations and automatic control and the same goes for routines. The idea that routines stabilize or even tranquilize organizational functioning has been present in the literature almost from the very beginning (March and Olsen 1989; Nelson and Winter 1982). Habitual and routine actions are also stable in the sense that they are more predictive than spontaneous actions (they reduce behavioral uncertainty).

(3) Repetition. Routines are repetitive inasmuch as habits are and this feature seems to be definitional for both of them. But there is a nuance. Take an example. An agent who enters into a new organization, say a newly employed professor at a university, is expected to perform certain administrative routines, but they are new to them. Thus, the agent (the new professor) may perform a given routine, although it is new to them and, in this sense, there is no repetition from the perspective of their actions. But the repetitive dimension still remains on the organizational macro-level: the new professor performs what other professors performed before in similar situations. This routine may also be replicated from one organization to another. Repetitiveness is thus crucial for habitual and routine behavior.

The list of similarities may be extended, but already the three features presented above reveal and take us directly to significant differences. The first one is also the main rationale for distinguishing them in organizational research.

(1) Collectivity. Routines are collective phenomena which appear on the organizational macro-level, while habits are dispositions of individual agents (and performances resulting from these dispositions), i.e. if habits appear in organizations, their presence can be detected only on the organizational micro-level of individuals. The repetitive, collective pattern or macro-disposition is something that can be ascribed only to the level of an organization or a cooperating group. For example, putting on a hardhat by an engineer in a construction zone could not be called a routine if it did not play its stabilizing and economizing roles in 
organizing and was not, as such, organizationally replicative. ${ }^{10}$

Further, even if one supposes that all agents who perform a routine, say serving refreshments in an aircraft (Kremser et al. 2019), do so habitually, in the sense that they are automatically-minded as individuals, the macro-level outcome to which they contribute may display different intentional properties due to the fact that it must additionally imply collective mechanisms related to automatic and/or planned coordination (see, e.g.: Knoblich et al. 2011). So, psychological habits may be directly related to organizational routines, but the organizational-collective level must also be considered to see a given habit as a part of an organizational capability or a pattern together with its roles. This issue situates the study of routines in the context of problems related to collective intentionality (in its automatic and deliberative forms), as well as in the context of purely habitual actions.

(2) Mindfulness. Despite their usually habitual underpinnings, routines may be performed with the full presence of deliberation and intentions, especially when they are complex and require significant attentional resources. Routines in nuclear power plants (Tveten and Thomassen 1975) or surgical routines in operating rooms (Seiden and Barach 2006) —where paying attention to minute details in action sequences matters a lot for the final outcome-cannot be completely automatic. Naturally, habitual inertia may always occur if a routine is simple and is repeated frequently enough, but on the macro-level many routines cannot be conceived as automatic, even if they are expected to increase organizational stability or imply macro-level inertia (Yi et al. 2016). Indeed, this is one of the reasons not only to consider the category of routines heterogenous, but also a source of practical complexity (I shall return to this issue in the last section).

(3) Changeability. Even if routines are expected to bring stability, they must be changeable. In fact, they are mutable and flexible due to the requirements of organizational performance (pressures towards effectiveness) which impose constraints on what can or should be changed. This feature is observed for example when old routines meet organizational novelty (unpredicted situations or technological transformations) and hence need adjustments and modifications. These modifications also require mindfulness: they may be the result of an instantaneous adjusting of the sub-goals of the whole routine to the requirements of changeable practice (for example, the way how a recruitment procedure is realized in response

\footnotetext{
${ }^{10}$ Naturally, there can be cases of pathological routines, for example when a worker follows an outdated procedure or defective rule. Such routines are organizationally disruptive (much like bad habits are psychologically harmful). This topic has not attracted attention from routines scholars who usually focus on organizationally positive (non-dysfunctional) aspects of routine behavior.

Notice also that, technically, purely individual routines could exist only if we wanted to distinguish them from those actions which are habitual i.e. automatically triggered by memory. Deliberately chosen reiterative activities pursued reflexively for some reason (e.g. reiterative forcing oneself to get up early in the morning to go jogging and get fit or taking a measured dose of medicine at a certain hour every day) would constitute a separate category of non-automatic actions which require routinization, but are not yet habitual (so they might be called: habits-before-habitization). An attempt to introduce this category to everyday language would amount to conceptual engineering and it would require good justification to begin with.
} 
to a change in the profile of candidates) or they may require agentive (e.g. managerial) intervention preceded by relevant pre-planning. In this sense, a routine may appear automatic when we consider its time-slice micro-enactments by individual agents, but on the macro-level of organizational processes and their dynamics, it may display a high degree of flexibility and changeability.

This conceptual feature appears particularly important for the proponents of the idea that routines are 'effortful accomplishments'. According to their view, the level of dynamic organizational practice is crucial for the very conceptualization of routines. But in the cognitive-psychological (intentional) perspective, it does not appear as necessary, and the question of routine change and flexibility can always be explained by micro-level psychological mechanisms (see the last section).

The changeability of routines is also significantly related to organizational learning. Once learned, psychological habits do not progress - they may be revised or changed due to environmental factors or intra-psychic forces, but it would be difficult to maintain that they can be improved. On the other hand, routines display the possibility of improvement as they are harnessed to knowledge transfer, organizational change and effectiveness (Levitt and March 1988; Becker 2017).

This short list of features that differentiate habits from routines again reveals the problem of conceptualization. From the sociological and practice theory perspective, the list would certainly be longer. For example, the authors in the 'routine dynamics' camp spent much time highlighting the fact that routines cannot be something fixed or automatic, because human practice is mutable and flexible. In the cognitive perspective, this problem is solved by different means, for example with the aid of the concept of socalled dynamic capability. Dynamic capability may be defined as an organizational "ability to integrate, build, and reconfigure internal and external competences to address rapidly changing environments" (Teece et al. 1997: 516). Dynamic capabilities are macro-level dispositions related, for example to cognitive abilities and resources of an organization which play complementary roles to operating and administrative routines. To oversimplify, routines bring standardization and automatization of organizational functioning, and dynamic capabilities provide its mindfulness and flexibility (cf. Schilke et al. 2018). Thus, picturing routines as either automatic or mindful is related to specific theoretical perspectives which may clash. ${ }^{11}$ Even if each of these perspectives is supported by distinct explanatory ambitions, misunderstandings between them are entirely possible. This points to the need for increased conceptual rigor in the organizational scholarship. ${ }^{12}$

Let us take stock. I have briefly examined similarities and differences between habits and routines showing that they are to some extent related to the problem of conceptualization. The issue that now calls for an explanation is the relation between them. The intentional conceptual apparatus and cognitive-psychological framework accepted in

\footnotetext{
${ }^{11}$ As noted (fn.1), the differences in conceptualizations (related to the differences between sociological and cognitive perspectives) gave birth to several attempts to show that there is no serious contradiction between them.

12 This problem is discussed in more detail in the context of conceptual engineering in (Makowski 2020a).
} 
the discussion above determine the type of that explanation. In other words, further discussion is not possible without explicitly accepting and developing an integrated approach towards habits and routines.

\section{Habits as Building Blocks of Routines-Organizational Perspective}

The idea that organizational routines are founded on (or built of) habits is quite popular in the literature (see: section 3.3.), but it may imply various theoretical stances, as the literature does not share one methodological perspective: psychological, sociological or economic. Also, it is worth noticing that methodologically liberal accounts explicitly mix those perspectives and edit the concept of habit to gain quick explanatory benefits. ${ }^{13}$ An illustrative example of such conceptual reengineering is the account of "the multiplicity of habit" by Turner and Cacciatori (2016). Their typology of habits is devised to explain how the intentional picture of routines changes with respect to the mind-infusion of habit and its contextual (in)variability. According to the authors, there are four types of habit, briefly: "automatic habits" (habits studied in psychology, performed in stable conditions, but uncontrolled by deliberation), "contested habits" (also studied in psychology, performed in stable environment, but controlled by deliberation and will), "skillful habits" (roughly amounting to motor skills studied in psychology, performed in unstable conditions, but characterized with the aid of the Bourdieusian sociology), and "infused habits" (habits saturated with deliberation, performed also in dynamic conditions - a theme from Deweyan pragmatism). From the perspective of psychological research, these four types of habit turn out to be folk names for phenomena the categories of which reduce to habits and motor skills, which are studied in relatively autonomous research streams. Thus, the very typology makes sense only when one mixes the perspectives of psychology, sociology and philosophy. ${ }^{14}$ But to maintain explanatory power there is no need to mix those perspectives and multiply entities beyond necessity.

Fortunately, scientific standards and the logic of inquiry do not oblige routine scholars to subscribe to such methodological liberalism. The nature of routines can be, therefore, explored either from a sociological or from a psychological viewpoint, without confusing them.

Although the decision to accept one of those viewpoints ultimately depends on scholarly preferences, psycho-cognitive research (aided by action theory) appears to be conceptually better suited when it comes to the explanation of key micro-level aspects of the intentionality of routines. Psychology offers more fine-grained analyses of attention, motor control and other lower cognitive processes which play their roles in individual and collective actions (see: sect. 3), so it should not be a surprise that social and cognitive psychology is widely utilized in empirically informed action theory.

The above methodological issue gives us sufficient reasons to discuss the concept of habit in the organizational context while staying on the grounds of psychology. But sticking with the psychological account of habit in organizational research still leaves open other methodological options related to the understanding of the relation between

\footnotetext{
${ }^{13}$ This and similar explanatory strategies are frequent in organizational research, probably due to the fact that the whole discipline is still methodologically young.

${ }^{14}$ For a more detailed analysis of this typology, see (Makowski 2020a).
} 
the psychological micro-level and the organizational macro-level. One needs to be aware of them when picturing the micro-level intentionality of routines. For the sake of convenience, I will divide these options into two groups of views. ${ }^{15}$ Let us call them the constitutive view and the causal view. ${ }^{16}$ Although all accounts from these two groups share certain basic intuitions concerning the micro-level of individual habits and the macro-level of routines, they are methodologically different when it comes to how the relation between them is conceived.

According to the first one, habits "build" routines. This is a basic metaphor for a constitutive relation. Constitution here means that micro-level properties related to habits build or affect macro-level phenomena (or, in a conditional formulation: any change on the micro-level would be correlated with changes on the macro-level). How should this constitution be understood more specifically? Let us note three options:

(1) Routines as collective, interlocking actions emerge from learned habitual dispositions stored in the procedural memory of individual agents (Cohen and Bacdayan 1994),

(2) the transformation of individual habits into routines is tied with the development of shared cognitive schemata that enable the cooperative level of routines (a view in the spirit of Dionysiou and Tsoukas (2013)),

(3) individual habits aggregate into routines as the collective dispositions of an organization: they are organizational meta-habits sustained by individual habits in an interlocking structure of cooperating individuals and the organizational environment in which routines are enacted (Hodgson 2003).

The causal view is represented by the aforementioned micro-foundations movement according to which the proper explanation of routines implies a reduction of the organizational macro-level to the micro-level factors (Felin et al. 2012; Felin et al. 2015; Felin and Hesterly 2007; Felin and Foss 2005). So, the psychological habits of individual agents who perform routines must play important causal roles for the possibility of the enactment of those routines. According to this view, the proper explanatory tactic for routines requires full consideration of causal chains with various micro-level organizational factors. If habits are performed on the micro-level, they causally co-determine the macro-level of routines. Thusly conceived, causalism is both metaphysically and epistemologically stronger than constitutivism although it may still be expressed in the same or very similar language (metaphors associated with building and foundations). ${ }^{17}$

All the above options reveal very interesting explanatory paths, but they also have significant limitations. To put it briefly, extant constitutivist approaches either do not sufficiently explain the mechanism of emergence of routines from individual habits (1),

\footnotetext{
${ }^{15}$ Here I purposively ignore those types of routines in which habituation does not appear or is minimal, i.e. in which routines roughly amount to mindful following procedures or rules which are pre-planned (consider again, for example, certain routines in nuclear power plants). Those types would require a separate methodological rubric.

${ }^{16}$ I borrow the terminology from Vromen (2010).

${ }^{17}$ The micro-foundations movement generated interesting controversy related to causalism. In short, the critique proposed by Vromen (Vromen 2010) has not convinced the proponents of microfoundations (Abell et al. 2010).
} 
do so at the cost of drifting to sociology which requires mixing research perspectives (subscribing methodological liberalism) (2), or they simply assume that the analogy between routines and habits within the framework of evolutionary economics is strong enough to explain the constitutive relation (3). All of them also seem to assume that habits constitute routines in a critical way. The latter condition may appear as too quick in the light of the intentional complexity of routines. As noted, they sometimes involve the automaticity of habits and sometimes they may also be possible only when fullyfledged decisions or intentions of performing reflexive individuals are in play. Mindfulness affects the macro-level picture of routines to an extent that the standard, automation-oriented perspective on the foundational role of habits does not seem to be sufficient (Feldman 2003). Similar worries concerning constitutivist views refer to those cases of routines in which individual habits are not yet formed and require entirely deliberative actions or, finally, to those cases in which the collective level requires additional cognitive mechanisms providing coordination or cooperation (such as priming mechanisms that appear between agents, their shared intentions, and other mental states that produce collective intentionality).

The causalist approach exemplified by the micro-foundations movement is immune to the criticism described in the last point, being open to including other micro-level factors than habits (for example, Felin et al. (2015) explicitly notice the role of shared intentions). Still, this program accepts the strong assumption that all micro-level factors must play causal roles. However natural it may be for an intentionalist to accept causalism (see: Schlosser 2011), the assumption that there are micro-macro causal links can be questioned. Causalism generates a number of troubles - not so much as a theory of mental content (cf. Adams and Aizawa 2017), but as a view regarding the links between psychology-level and organization-level phenomena (Vromen 2010; Hodgson and Knudsen 2011). Because they emerge, the intentional properties of the latter need not be the same as the intentional properties of the former (Harper and Lewis 2012).

Both constitutivism and and causalism display drawbacks when it comes to the micro-macro relations as well as their understanding of the micro-level factors in those relations. In part, such limitations strengthened the interest in the practical dynamics of routines. Although the level of performance or enactment is crucial for the empirical properties of specific routines (and, hence, the possibility of empirical studies which accept the sociological lens), the intentional micro-level factors must still play their role in routine dynamics. The reasons for investigating those factors further do not disappear even if the role and import of the practical complexity and dynamics of routines seem to override the challenges related to typical 'building-block' approaches to the micromacro relations.

\section{Towards the Intentional Complexity: Habits and Micro-Level Mindfulness}

The issue of the complexity of routines has recently been noticed within the framework of routine dynamics (Hærem et al. 2021), but - as is typical for this lens - it does not embrace the question of organizational intentionality and its micro-level aspects. On the other hand, organizational intentionality has been explicitly studied in economics, but 
mainly in the context of planned action (Muñoz and Encinar 2014; Muñoz et al. 2011). Individual intentions, plans and deliberate goal-striving certainly play important roles on the organizational level, including routines (Dittrich and Seidl 2018; Bapuji et al. 2012), but they cannot exhaustively account for their intentional complexity. In the case of routines, the picture of that complexity must embrace not only the microfoundational role of habits, but also adequately deal with the complexity of routines on the macro-level of practice, which implies their mindfulness and mutability.

This reveals the need for conceptual development and refinement at the psychocognitive level. Such development may be obtained through the exploration of the micro-level factors that suitably account for the issue of routine mindfulness. From the perspective of psychological research, a natural way to enrich the picture of the intentional complexity of routines is psychological mindfulness (psychological flexibility).

However the idea that many routines can be perceived as automatic or habitual makes sense from a certain point of view (see: section 3.3), the organizational dynamics of routines reveals that they may require mindfulness (to avoid errors, to maintain productivity, warrant conditions for change, etc.). Although the role of mindfulness is an important theme in routines research and in organizational learning (Levinthal and Rerup 2006; Ray et al. 2011; Kudesia 2019), its micro-level intentional underpinnings have not been studied. Let us, therefore, briefly show how mindfulness changes the intentional picture of the habitual underpinnings of the routines described above.

Seen from the psychology of flexibility perspective (Kashdan and Rottenberg 2010), habits belong to the class of default mental states, which economize agency and provide useful heuristics for action. Without them, agents would always need to use their standard deliberative, attentional and computational resources to act as effective individuals and groups. This would often amount to wasting time and energy. Of course, as is well known in the psychology of habit, excessive reliance on habits produces inertia, slips, rigid keeping to one course of action and other unwelcome consequences (Aarts and Dijksterhuis 2000). This is why the full psychological picture of habits needs to account for deliberative goal-striving that balances those harmful effects (see the three-pronged model, section 3.2.). But it is not possible to fully explain the psycho-cognitive basis of mindfulness (or flexibility) by referring solely to the dynamics of deliberative goal-striving and planning; the issue is complex on the individual level and involves inhibitory control, working memory, attentional resources, logical and relational reasoning and cognitive flexibility studied together under the heading of executive functions (Diamond 2013). Individual personality configurations may also weaken or strengthen mindfulness (Kashdan and Rottenberg 2010). Overall, mindfulness seems to be no less important than habits if one wants to comprehensively understand the intentional micro-foundations of changeability and the macro-level mindfulness of routines (and other organizational phenomena). In other words, the fact that routines may display flexibility and mindfulness on the organizational macro-level must be to a certain degree micro-founded in agentive mindfulness which provides the conditions for meta-control of more automatic modes of functioning. We may briefly define such mindfulness as a personal capacity to adapt that consists of four dynamic psychological processes: (1) adaptation to changing environment, (2) reconfiguration of mental assets, (3) perspective shifting, and (4) balancing competing motivations and needs (cf. Kashdan and Rottenberg 2010). 
In this perspective, individual tendencies to rely on habits belong to the picture of individual mindfulness. So, if psychological habits play a micro-foundational role for the intentional image of routines, then mindfulness should also be considered here in order to properly understand their complexity. Mindfulness is responsible for the intentional complexity of routines mainly because it provides the psycho-cognitive mechanism according to which the "the cognitive-automatic control gradient" (Pacherie and Mylopoulos 2020) leans more toward automaticity or more in the opposite direction allowing for more flexible forms of action. This suggests a broad spectrum of psycho-cognitive gears of behavioral meta-control control, adaptive mechanisms and shifts in perspective which together constitute the integrative mechanism behind the selection of more habitual or more deliberatively loaded forms of action suitable for practical contexts. In this sense, mindfulness is potentially of interest to psychology-based action theory which explores so-called 'heterarchical' mechanisms of action control (Cushman and Morris 2015), typical for example of motor skills (Pacherie and Mylopoulos 2020). The difference here is that those mechanisms matter for collective forms of action. The heterarchical approach to control implies more complexity than standard habit-based approaches - in psychology (Wood and Rünger 2016) and in organizational research (Louis and Sutton 1991) - usually suggest.

Of course, the shape of the proposed intentional lens should be perceived only as one of the answers one may formulate by exploring cognitive-psychological factors that affect the micro-level of routine actions. This perspective introduces one to intentional underpinnings of routine actions which integrate different modes of micro-level behavioral control. Notwithstanding how one solves methodological issues related to emergence, constitution or causation which typically appear in routines research, these micro-level intentional factors must somehow be embraced as they affect the way routine actions are performed as organizational phenomena.

Finally, the proposed picture is not, by itself, interesting only for the philosophy of collective intentionality and action. It also significantly advances current knowledge on the complexity of routines. For example, according to the review of (Hærem et al. 2021), there are three approaches to complexity allowing one to carry out empirical studies on routines: idealized, perceptual and enacted. The first one refers to an invariant characteristic of a given routine that allows its identification ("a function of idealized characteristics"), the second one focuses on agentive perceptions of microactivities and tasks performed in routines, and the third one explores the performative dimension of routines, i.e. what is done after a routine has been enacted by routine agents ("a function of enactments"). According to their observations, early studies focused mostly on the perceived complexity and only a few of them acknowledged complexity as an objective dimension of routines. On the other hand, currently the most popular sociological and empirically oriented perspective recognizes the complexity on the practical, enacted level. Their review does not mention the issue of the intentional complexity of routine behavior.

In this context, a focus on intentionality informed by the philosophy of action turns out to be a distinct approach to complexity. Its primary explanatory role is to initially reveal the psycho-cognitive scaffolding on which the micro-level performance or enactment of routine actions stands. The micro-level intentional dynamics of routines is correlated to their practical macro-level dynamics (in this sense, it supplements the third approach described above). Of course, there are also reasons to think that the 
perspective of intentional complexity may also contribute to better understanding and chances for identification of routines - both for the agents who perform them and for theorists. More fine-grained approaches to practical phenomena usually enrich the way think of them, and that is certainly the case for routines (Felin et al. 2012; Hærem et al. 2021).

The challenge that still remains salient in the context of the popularity of sociological empirically oriented approaches is related to the impact the intentional perspective is capable of making on the level of empirical studies. The insight that the complexity of the psychological profiles of organizational actors affects the macro-level shape of routines they perform, favoring increased habitization or mindfulness may be studied further. This is an unexplored avenue of empirical research in organizational psychology. ${ }^{18}$

\section{Conclusion}

In this paper, I approached the question of organizational intentionality through the prism of routines to shed a new light on their complexity. Basically, I wanted to show how routines differ from habits in cognitive-psychological research and highlight the idea that an account of micro-level mindfulness should be included in the picture of routines to properly understand the underpinnings of their intentional complexity. So far, the similarities and differences between habits and routines have not yet been studied more systematically. The intentional picture of routines is richer than the one of psychological habits. The obvious reason for this is that routines are organizational actions and actions of organized collectives, while habits are dispositions and actions of individuals. Nevertheless, if one decides to investigate their intentionality in an integrated approach, assuming that there must be some sort of meaningful relation between them in the organizational context, this conceptual decision proves fruitful. Engaging the modern psychology of habit and automaticity in the explanatory strategy turns out to be especially important. These streams of research offer one of the most promising paths in the explorations of the intentional micro-level underpinnings of routine behavior, although they certainly cannot exhaust them. Indeed, this perspective only reveals how convoluted those underpinnings are with respect to the problem of the mindfulness of routines. The intentional picture must embrace it. The account of psychological flexibility (mindfulness) - introduced as conceptually tied to behavioral automaticity in the last section-aims to solve this problem. The micro-level processes of mindfulness turn out to be one of the key factors affecting the complexity of routines. The intentional perspective on that complexity is the contribution philosophy of action makes not only to the philosophy of collective intentionality, but also to routines research as a part of the social sciences studying organizational behavior.

\footnotetext{
18 The challenges to studying the impact of the micro-level habits and psychological flexibility on the organizational macro-level of routines require separate methodological attention. Some of the key issues are described in (Makowski 2020b).
} 
Acknowledgements Work on this paper has been supported by National Science Centre, Poland, Grant No. 2018/29/B/HS4/01824.

Open Access This article is licensed under a Creative Commons Attribution 4.0 International License, which permits use, sharing, adaptation, distribution and reproduction in any medium or format, as long as you give appropriate credit to the original author(s) and the source, provide a link to the Creative Commons licence, and indicate if changes were made. The images or other third party material in this article are included in the article's Creative Commons licence, unless indicated otherwise in a credit line to the material. If material is not included in the article's Creative Commons licence and your intended use is not permitted by statutory regulation or exceeds the permitted use, you will need to obtain permission directly from the copyright holder. To view a copy of this licence, visit http://creativecommons.org/licenses/by/4.0/.

\section{References}

Aarts, Henk, and Ap Dijksterhuis. 2000. Habits as knowledge structures: Automaticity in goal-directed behavior. Journal of Personality and Social Psychology 78 (1): 53-63.

Abell, Peter, Teppo Felin, and Nicolai Foss. 2010. Causal and constitutive relations, and the squaring of Coleman's diagram: Reply to Vromen. Erkenntnis 73 (3): 385-391.

Adams, Fred, and Ken Aizawa. 2017. Causal theories of mental content. In The Stanford Encyclopedia of Philosophy (Summer 2017 Edition), ed. Edward N. Zalta: Stanford UP.

Ashforth, Blake E., and Yitzhak Fried. 1988. The mindlessness of organisational behaviors. Human Relations 41 (4): 305-329.

Bapuji, Hari, Manpreet Hora, and Akbar M. Saeed. 2012. Intentions, intermediaries, and interaction: Examining the emergence of routines. Journal of Management Studies 49 (8): 1586-1607.

Bargh, John A. 1994. The four horsemen of automaticity: Awareness, intention, efficiency, and control in social cognition. In Handbook of social cognition, ed. R. Wyer and T. Srull, 1-40. Lawrence Erlbaum.

Bargh, John A. 1996. Automaticity in action: The unconscious as repository of chronic goals and motives. In The psychology of action: Linking cognition and motivation to behavior, ed. P. Gollwitzer and John A. Bargh, 457-471. New York: Guilford.

Becker, Markus C. 2005. The concept of routines: Some clarifications. Cambridge Journal of Economics 29 (2): 249-262.

Becker, Markus C. 2017. Organizational routines and organizational learning. In The Oxford Handbook of Group and Organizational Learning, eds. Linda Argote, and John M. Levine. Oxford University Press.

Brownstein, Michael. 2014. Rationalizing flow: Agency in skilled unreflective action. Philosophical Studies 168 (2): 545-568.

Chaiken, Shelly, and Yaacov Trope. 1999. Dual-process theories in social psychology. Guilford Press.

Cohen, Michael D. 2007. Reading Dewey: Reflections on the study of routine. Organization Studies 28 (5): 773-786.

Cohen, Michael D. 2012. Perceiving and remembering routine action: Fundamental micro-level origins. Journal of Management Studies 49 (8): 1383-1388.

Cohen, Michael D., and Paul Bacdayan. 1994. Organizational routines are stored as procedural memory: Evidence from a laboratory study. Organization Science 5 (4): 554-568.

Cohen, Michael D., Daniel A. Levinthal, and Massimo Warglien. 2014. Collective performance: Modeling the interaction of habit-based actions. Industrial and Corporate Change 23 (2): 329-360.

Cushman, Fiery, and Adam Morris. 2015. Habitual control of goal selection in humans. Proceedings of the National Academy of Sciences 112 (45): 13817-13822.

Danner-Schröder, Anja. 2020. Without actors, there is no action: How interpersonal interactions help to explain routine dynamics. Review of Managerial Science. https://doi.org/10.1007/s11846-020-00408-X.

Davidson, Donald. 1963. Actions, reasons, and causes. Journal of Philosophy 60 (23): 685-700.

Dewey, John. 1922. Human nature and conduct, an introduction to social psychology. Vol. 17. Henry Holt \& Co..

Dezfouli, Amir, Nura W. Lingawi, and Bernard W. Balleine. 2014. Habits as action sequences: Hierarchical action control and changes in outcome value. Philosophical Transactions of the Royal Society B: Biological Sciences 369 (1655): 20130482.

Di Nucci, Ezio. 2013. Mindlessness. Newcastle: Cambridge Scholars Press.

Diamond, Adele. 2013. Executive functions. Annual Review of Psychology 64 (1): 135-168. 
Dionysiou, Dionysios D., and Haridimos Tsoukas. 2013. Understanding the (re)creation of routines from within: A symbolic interactionist perspective. Academy of Management Review 38 (2): 181-205.

Dittrich, Katharina, and David Seidl. 2018. Emerging intentionality in routine dynamics: A pragmatist view. Academy of Management Journal 61 (1): 111-138.

Dosi, Giovanni, Eric A. Nelson, and Sidney Winter. 2000. Introduction: The nature and dynamics of organisational capabilities. In The nature and dynamics of Organisational capabilities, ed. Giovanni Dosi, Eric A. Nelson, and Sidney Winter, 1-22. Oxford University Press.

Douskos, Christos. 2017a. Habit and intention. Philosophia 45 (3): 1129-1148.

Douskos, Christos. 2017b. The spontaneousness of skill and the impulsivity of habit. Synthese 196 (10): 4305-4328.

Eggers, J.P., and Sarah Kaplan. 2013. Cognition and capabilities: A multi-level perspective. Academy of Management Annals 7 (1): 295-340.

Feldman, Martha S. 2000. Organizational routines as a source of continuous change. Organization Science 11 (6): $611-629$.

Feldman, Martha S. 2003. A performative perspective on stability and change in organizational routines. Industrial and Corporate Change 12 (4): 727-752.

Feldman, Martha S. 2016. Routines as process: Past, present and future. In Organizational routines. How they are created, maintained, and changed, ed. Jennifer Howard-Grenville, Claus Rerup, Ann Langley, and Haridimos Tsoukas, 23-46. Oxford University Press.

Feldman, Martha S., Luciana D’Adderio, Katharina Dittrich, and Paula Jarzabkowski. 2019. Routine dynamics in action: Replication and transformation. In In Research in the Sociology of Organizations. Emerald.

Feldman Martha, S., and Wanda J. Orlikowski. 2011. Theorizing practice and practicing theory. Organization Science 22 (5): 1240-1253.

Feldman, Martha S., and Brian T. Pentland. 2003. Reconceptualizing organizational routines as a source of flexibility and change. Administrative Science Quarterly 48 (1): 94-118.

Feldman, Martha S., Brian T. Pentland, Luciana D'Adderio, and Nathalie Lazaric. 2016. Beyond routines as things: Introduction to the special issue on routine dynamics. Organization Science 27 (3): 505-513.

Feldman, Martha S., Brian T. Pentland, Luciana D'Adderio, Katharina Dittrich, Claus Rerup, and David Seidl. 2021. Cambridge handbook of routine dynamics. Cambridge University Press.

Felin, Teppo, Nicolai Foss, Koen H. Heimeriks, and Tammy L. Madsen. 2012. Microfoundations of routines and capabilities: Individuals, processes, and structure. Journal of Management Studies 49 (8): 1351-1374.

Felin, Teppo, and Nicolai J. Foss. 2005. Strategic organization: A field in search of micro-foundations. Strategic Organization 3 (4): 441-455.

Felin, Teppo, Nicolai J. Foss, and Robert E. Ployhart. 2015. The microfoundations movement in strategy and organization theory. The Academy of Management Annals 9 (1): 575-632.

Felin, Teppo, and William S. Hesterly. 2007. The knowledge-based view, nested heterogeneity, and new value creation: Philosophical considerations on the locus of knowledge. Academy of Management Review 32 (1): 195-218.

Fiedler, Klaus, and Mandy Hütter. 2014. The limits of automaticity. In Dual process theories of the social mind, ed. J. Sherman, B. Gawronski, and Y. Trope, 497-513. Guilford Press.

Foss, Nicolai J., and Stefan Linder. 2019. Microfoundations: Nature, debate, and promise. Cambridge University Press.

Fox, Stephen. 2006. 'Inquiries of every imaginable kind': Ethnomethodology, practical action and the new socially situated learning theory. The Sociological Review 54 (3): 426-445.

Gao, D., X. Deng, and B. Bai. 2014. The emergence of organizational routines from habitual behaviours of multiple actors: An agent-based simulation study. Journal of Simulation 8 (3): 215-230.

Gardner, Benjamin, L. Alison Phillips, and Gaby Judah. 2016. Habitual instigation and habitual execution: Definition, measurement, and effects on behaviour frequency. British Journal of Health Psychology 21 (3): 613-630.

Hærem, Thorvald, Jeong Yooeun, and Mathias Hansson. 2021. Complexity in routine dynamics. In Cambridge Handbook of Routine Dynamics, eds. Martha S. Feldman, Brian T. Pentland, Luciana D'Adderio, Katharina Dittrich, Claus Rerup, and David Seidl. Cambridge: Cambridge University Press.

Harper, David A., and Paul Lewis. 2012. New perspectives on emergence in economics. Journal of Economic Behavior \& Organization 82 (2): 329-337.

Hay, Janine F., and Larry L. Jacoby. 1996. Separating habit and recollection: Memory slips, process dissociations, and probability matching. Journal of Experimental Psychology: Learning, Memory, and Cognition 22 (6): 1323-1335.

Hay, Janine F., and Larry L. Jacoby. 1999. Separating habit and recollection in young and older adults: Effects of elaborative processing and distinctiveness. Psychology and Aging 14: 122-134.

Healy, Kieran. 2017. Fuck nuance. Sociological Theory 35 (2): 118-127. 
Hodgson, Geoffrey M. 2003. The mystery of the routine: The Darwinian destiny of an evolutionary theory of economic change. Revue économique 54 (2): 355-384.

Hodgson, Geoffrey M., and Thorbjorn Knudsen. 2011. Poverty of stimulus and absence of cause: Some questions for Felin and Foss. Journal of Institutional Economics 7 (2): 295-298.

Kashdan, Todd B., and Jonathan Rottenberg. 2010. Psychological flexibility as a fundamental aspect of health. Clinical Psychology Review 30 (7): 865-878.

Knoblich, Guenther, Stephen Butterfill, and Natalie Sebanz. 2011. Psychological research on joint action: Theory and data. In The psychology of learning and motivation, ed. Brian Ross, 59-101. Academic Press.

Knudsen, Thorbjørn. 2008. Organizational routines in evolutionary theory. In Handbook of organizational routines, ed. Markus C. Becker, 125-151. Edward Elgar.

Kremser, Waldemar, Brian Pentland, and Sabine Brunswicker. 2019. Interdependence within and between routines: A performative perspective. In Routine Dynamics in Action: Replication and Transformation, eds. S. Feldman Martha, D’Aderio Luciana, Dittrich Katharina, and Jarzabkowski Paula, 79-98. Research in the sociology of organizations: Emerald Publishing Limited.

Kudesia, Ravi S. 2019. Mindfulness as metacognitive practice. Academy of Management Review 44: 405-423.

Labrecque, Jennifer S. 2015. Habits as friend and foe to self-control: The dual roles of routinized behavior. Doctoral Dissertation, University of Southern California.

Labrecque, Jennifer S., Wendy Wood, David T. Neal, and N. Harrington. 2017. Habit slips: When consumers intentionally resist new products. Journal of the Academy of Marketing Science 45 (1): 119-133.

Levinthal, Daniel, and Claus Rerup. 2006. Crossing an apparent chasm: Bridging mindful and less-mindful perspectives on organizational learning. Organization Science 17 (4): 502-513.

Levitt, Barbara, and James G. March. 1988. Organizational learning. Annual Review of Sociology 14: 319-340.

Logan, Gordon D. 1985. Skill and automaticity: Relations, implications, and future directions. Canadian Journal of Philosophy 39 (2): 367-386.

Louis, Meryl Reis, and Robert I. Sutton. 1991. Switching cognitive gears: From habits of mind to active thinking. Human Relations 44 (1): 55-76.

Makowski, Piotr T. 2017. Tadeusz Kotarbiński's action theory - Reinterpretive studies. Palgrave-Macmillan.

Makowski, Piotr T. 2020a. Conceptual engineering in the field of management. The case of routines research. Academy of Management Review. https://doi.org/10.5465/amr.2019.0252.

Makowski, Piotr T. 2020b. Making sense of the psycho-cognitive microfoundations of organizational routines. Academy of Management Proceedings. https://doi.org/10.5465/AMBPP.2020.13148abstract,2020,13148.

March, J.G., and H.A. Simon. 1958. Organizations. Wiley.

March, James G., and Johan P. Olsen. 1989. Rediscovering institutions: The organizational basis of politics. The Free Press.

Moors, Agnes, and Jan De Houwer. 2006. Automaticity: A theoretical and conceptual analysis. In Psychological Bulletin 2: 297-326.

Muñoz, Félix-Fernando, and María-Isabel Encinar. 2014. Intentionality and the emergence of complexity: An analytical approach. Journal of Evolutionary Economics 24 (2): 317-334.

Muñoz, Félix-Fernando, María-Isabel Encinar, and Carolina Cañibano. 2011. On the role of intentionality in evolutionary economic change. Structural Change and Economic Dynamics 22 (3): 193-203.

Muraven, Mark, R. Lorraine Collins, Saul Shiffman, and Jean A Paty. 2005. Daily fluctuations in self-control demands and alcohol intake. Psychology of Addictive Behaviors 19 (2):140-147.

Neal, D.T., W. Wood, and A. Drolet. 2013. How do people adhere to goals when willpower is low? The profits (and pitfalls) of strong habits. Journal of Personality and Social Psychology 104 (6): 959-975.

Neal, David T., and Wendy Wood. 2009. Automaticity in situ and in the lab: The nature of habit in daily life. In Ezequiel Morsella, John a. Bargh, and Peter M. Gollwitzer, 442-457, ed. Oxford Handbook of Human Action. Oxford University Press.

Neal, David T., Wendy Wood, Jennifer S. Labrecque, and Phillippa Lally. 2012. How do habits guide behavior? Perceived and actual triggers of habits in daily life. Journal of Experimental Social Psychology 48 (2): $492-498$.

Nelson, Richard R., and Sidney G. Winter. 1982. An evolutionary theory of economic change. The Belknap Press / Harvard University Press.

Norman, Donald A. 1981. Categorization of action slips. Psychological Review 88 (1): 1-15.

Orbell, Sheina, and Bas Verplanken. 2010. The automatic component of habit in health behavior: Habit as cue-contingent automaticity. Health Psychology 29 (4): 374-383.

Orbell, Sheina, and Bas Verplanken. 2015. The strength of habit. Health Psychology Review 9 (3): 311-317.

Pacherie, Elisabeth, and Myrto Mylopoulos. 2020. Beyond automaticity: The psychological complexity of skill. Topoi. https://doi.org/10.1007/s11245-020-09715-0.

Parmigiani, Anne, and Jennifer Howard-Grenville. 2011. Routines revisited: Exploring the capabilities and practice perspectives. The Academy of Management Annals 5 (1): 413-453. 
Pentland, Brian T., and Henry H. Rueter. 1994. Organizational routines as grammars of action. Administrative Science Quarterly 39 (3): 484-510.

Quinn, Jeffrey M., Anthony Pascoe, Wendy Wood, and David T. Neal. 2010. Can't control yourself? Monitor those bad habits. Personality and Social Psychology Bulletin 36 (4): 499-511.

Railton, Peter. 2009. Practical competence and fluent agency. In Reasons for action, ed. David Sobel and Steven Wall, 81-115. Cambridge University Press.

Ray, Joshua L., Lakami T. Baker, and Donde Ashmos Plowman. 2011. Organizational mindfulness in business schools. Academy of Management Learning \& Education 10 (2): 188-203.

Saling, L.L., and J.G. Phillips. 2007. Automatic behaviour: Efficient not mindless. Brain Research Bulletin 73 (1): $1-20$.

Schilke, Oliver, Songcui Hu, and Constance E. Helfat. 2018. Quo vadis, dynamic capabilities? A contentanalytic review of the current state of knowledge and recommendations for future research. Academy of Management Annals 12 (1): 390-439.

Schlosser, Markus. 2020. Dual-system theory and the role of consciousness in intentional action. In Free Will, Causality, and Neuroscience, eds. Bernard Feltz, Marcus Missal, and Andrew Sims, 35-56. Brill.

Schlosser, Markus E. 2011. Agency, ownership, and the standard theory. In New waves in philosophy of action, ed. Jesús H. Aguilar, Andrei A. Buckareff, and Keith Frankish, 13-31. London: Palgrave Macmillan UK.

Schwabe, Lars, and Oliver T. Wolf. 2010. Socially evaluated cold pressor stress after instrumental learning favors habits over goal-directed action. Psychoneuroendocrinology 35 (7): 977-986.

Schwabe, Lars, and Oliver T. Wolf. 2013. Stress and multiple memory systems: From thinking to doing. Trends in Cognitive Sciences 17 (2): 60-68.

Seiden, Samuel C., and Paul Barach. 2006. Wrong-side/wrong-site, wrong-procedure, and wrong-patient adverse events: Are they preventable? JAMA Surgery 141 (9): 931-939.

Smith, Kyle S., and Ann M. Graybiel. 2013. A dual operator view of habitual behavior reflecting cortical and striatal dynamics. Neuron 79 (2): 361-374.

Stanley, Jason, and John Krakauer. 2013. Motor skill depends on knowledge of facts. Frontiers in Human Neuroscience 7 (503): 1-11.

Teece, David J., Gary Pisano, and Amy Shuen. 1997. Dynamic capabilities and strategic management. Strategic Management Journal 18 (7): 509-533.

Turner, Scott F., and Eugenia Cacciatori. 2016. The multiplicity of habit: Implications for routines research. In Organizational routines: How they are created, maintained, and changed, ed. Jennifer A. HowardGrenville, Claus Rerup, Ann Langley, and Haridimos Tsoukas, 71-95. Oxford: Oxford University Press.

Tveten, U., and D. Thomassen. 1975. Routine operation of nuclear power plants. Fra Fysikkens Verden 37 (3): 58-66.

Verplanken, Bas. 2006. Beyond frequency: Habit as mental construct. British Journal of Social Psychology 45 (3): $639-656$.

Vromen, Jack. 2010. MICRO-foundations in strategic management: Squaring Coleman's diagram. Erkenntnis 73 (3): 365-383.

Winter, Sidney G. 2013. Habit, deliberation, and action: Strengthening the microfoundations of routines and capabilities. The Academy of Management Perspectives 27 (2): 120-137.

Witt, Ulrich. 2011. Emergence and functionality of organizational routines: An individualistic approach. Journal of Institutional Economics 7 (2): 157-174.

Wood, Wendy. 2017. Habit in personality and social psychology. Personality and Social Psychology Review 21 (4): 389-403.

Wood, Wendy, Jennifer S. Labrecque, Pei-Ying Lin, and Dennis Rünger. 2014. Habits in dual process models. In Dual process theories of the social mind, ed. B. Gawronski, J. Sherman, and Y. Trope, 371-385. Guilford.

Wood, Wendy, and Dennis Rünger. 2016. Psychology of habit. Annual Review of Psychology 67 (1): 289314.

Yi, Sangyoon, Thorbjørn Knudsen, and Markus C. Becker. 2016. Inertia in routines: A hidden source of organizational variation. Organization Science 27 (3): 782-800.

Zollo, Maurizio, and Sidney G. Winter. 2002. Deliberate learning and the evolution of dynamic capabilities. Organization Science 13 (3): 339-351.

Publisher's Note Springer Nature remains neutral with regard to jurisdictional claims in published maps and institutional affiliations. 